OPEN ACCES

\title{
Green Simplistic Biosynthesis of Anti- Bacterial Silver Nanoparticles Using Annona Squamosa Leaf Extract
}

\author{
Singaravelu Senthamilselvi ${ }^{*, 1}$, Ponnuchamy Kumar ${ }^{2}$, Alagiyamanavalan Lakshmi Prabha ${ }^{1}$, Munisamy Govindaraju ${ }^{2}$ \\ ${ }^{1}$ Department of Plant Science, School of Life Sciences. Bharathidasan University, Tiruchirappalli - 620024. \\ ${ }^{2}$ Department of Environmental Biotechnology, School of Environmental Sciences, Bharathidasan University, Tiruchirappalli - 620024. \\ * Corresponding author: Singaravelu Senthamilselvi (ssenthamilselvi12@gmail.com) Tel/fax.: +91-9443688336
}

\begin{abstract}
Green nanotechnology involves the synthesis of nanoparticles without the involvement of toxic chemicals. The present study reports the green synthesis of silver nanoparticles from Annona squamosa leaf extract rapidly within 20 min. High throughput characterization such as UV-vis spectroscopy, Fourier Transform-Infrared Spectroscopy (FT-IR), Transmission Electron Microscopy (TEM), Field Emission-Scanning Electron Microscopy (FE-SEM), X-ray diffraction (XRD) and Zeta potential measurements disclose the existence of silver nanoparticles. The phenolic compounds present in the aqueous leaves extract paves way for the possible reduction of silver to nano-silver. Electron microscopic studies revealed the average size of nanoparticles were $52 \mathrm{~nm}$. The nanoparticles are highly stable by reaching a zeta potential value of $-33.6 \mathrm{mV}$. Comparative antibacterial efficacy of silver nanoparticles was investigated by disk diffusion and microtitre broth dilution method against Escherichia coli. The result showed that silver nanoparticles are toxic to $E$. coli cells at higher concentration. Overall, we suggest microtitre broth dilution method is more reliable to determine the antimicrobial activity of silver nanoparticles than disk diffusion method.
\end{abstract}

Keywords: Green nanotechnology, Annona squamosa, E. coli, disk diffusion, microtitre broth dilution method

Citation: S. Senthamilselvi et al. Green Simplistic Biosynthesis of Anti-bacterial Silver Nanoparticles Using Annona Squamosa Leaf Extract. Nano Biomed. Eng. 2013, 5(2), 102-106.

DOI: $10.5101 /$ nbe.v5i2.p102-106.

\section{Introduction}

In recent trends, green nanotechnology is gaining more attention among researchers due to its importance in eliminating the use of toxic chemicals and efficient synthesis of nanomaterials [1]. Notably, metal nanoparticles from bacteria and plants has initiated a new era in the history of nanoparticle synthesis. Moreover, fabricating nanomaterials by "green approach" have less impact on the environment and minimize health associated risks [2]. Significant attempts have been made to synthesis nanostructures with controlled size, shape and properties using biological methods [3]. Conversely, only a few cases report extensive applications in the field of biomedicine and pharmacy [4]. Therefore, designing a precise and powerful nanostructure is mandatory to overcome synthetic materials. Nowadays, nanoparticles of silver, gold, platinum, palladium etc., have been synthesized from plants of natural origin [5]. Among the different nanoparticles synthesized, silver has a remarkable application in the field of sensors, biolabelling, filters, cell electrodes and antimicrobials [6].

Annona squamosa L. is a multipurpose semideciduous small tree and mostly distributed in America and Asia.

It shows varied medicinal effects including antibacterial, anti-hyperglycemic, anti-genotoxic, antihyperlipidemic, anti-oxidant, anti-head lice, anti-diabetic, hepatoprotective, anti-tumour and insecticidal activity [7]. Naturally, A. squamosa contain pharmacologically important compounds for potential biomedical applications. In recent years, secondary metabolites belonging to several categories like alkaloids, flavonoids, diterpeniods and phenolic compounds have been studied and published [8]. Hence, in the present study an effort is made to biosynthesis silver nanoparticles rapidly using A. squamosa leaf extract. We have also evaluated the antibacterial activity of silver nanoparticles synthesized from A. squamosa on Escherichia coli by in-vitro methods such as disk diffusion and broth dilution method.

\section{Materials and methods}

\subsection{Preparation of aqueous leaf extract}

Well matured leaves of $A$. squamosa were collected from Bharathidasan University campus, Tamil Nadu, India. The leaves were surface sterilized with distilled 
water, cut into small pieces followed by shade drying for a period of 15 days. The dried materials were grounded into a fine powder by a mixer grinder. A mixture of 200 $\mathrm{mg}$ of powdered leaves in $100 \mathrm{ml}$ of distilled water was heated to $60^{\circ} \mathrm{C}$ for $20 \mathrm{~min}$ [9]. The extract obtained was filtered through Whatmann No. 1 filter paper pursued by $0.45 \mu \mathrm{m}$ sized filters.

\subsection{Biosynthesis of silver nanoparticles}

For biosynthesis of silver nanoparticles, a blend of 100 $\mu \mathrm{l}$ of $1 \mathrm{mM}$ silver nitrate and $99.99 \mathrm{ml}$ of aqueous leaf broth was heated at $60^{\circ} \mathrm{C}$ until no further colour change. The colour intensity of colloidal solution gradually increased by the effect of temperature [10]. Precisely after $20 \mathrm{~min}$, there is no change in colour indicates the completion of nanoparticle formation.

\subsection{Characterization of silver nanoparticles}

The biosynthesized silver nanoparticles were well characterized by high throughput techniques as follows: The optical properties of silver nanoparticles were monitored by a Shimadzu, UV-2450 spectrophotometer at a resolution of $1 \mathrm{~nm}$, between 200-800 nm using 10 $\mathrm{mm}$ optical path-length-quartz cuvettes. The molecular functional groups as phyto-constituents present in the silver nanoparticles were determined by Fourier Transform-Infrared studies (FT-IR). FT-IR analysis was carried out by spectrum RX-1 instrument in diffuse reflectance mode operated at a resolution of $4 \mathrm{~cm}^{-1}$ of wavelength of about $4000-400 \mathrm{~cm}^{-1}$ using $\mathrm{KBr}$ pellets. Morphological studies of nanoparticles were done by Transmission Electron Microscope (TEM) and Field Emission-Scanning Electron Microscope (FE-SEM) analysis. TEM images were acquired on a TECHNAI instrument operated at an accelerating voltage of 80 keV. FE-SEM analysis (Carl Zeiss, SIGMA) was done by preparing a thin film of sample onto a copper grid and then allowed to dry using a mercury lamp, prior to measurement. XRD measurements were carried out using a Philps 86 X'Pert Pro X-ray diffractometer by preparing a thin film on glass substrate. Malvern Zetasizer (Nano ZS90, UK) instrument was used to analyse the surface charge (stability) of biosynthesized nanoparticles.

\subsection{Antibacterial activity against $E$. coli}

The antimicrobial susceptibility of silver nanoparticles against E. coli (MTCC 1687) was evaluated by disk diffusion and microtitre broth dilution method as follows:

\subsubsection{Disk diffusion method}

Disk diffusion assay was adopted to determine the antimicrobial susceptibility of silver nanoparticles [11]. Freshly prepared, Luria bertani (LB) agar plates were swabbed with E. coli. The sterile disk (HIMEDIA) of $6 \mathrm{~mm}$ was loaded with different volumes of silver nanoparticles $(5,10,15,20$ and $25 \mu 1)$. The plates were incubated at $37^{\circ} \mathrm{C}$ for $24 \mathrm{~h}$ for determining the Zone of Inhibition (ZoI).

\subsubsection{Microtitre broth dilution method}

For microtitre broth dilution [12], sterile 96-well microtitre plates were dispensed with $100 \mu \mathrm{l}$ of LB broth. Pipette out $100 \mu \mathrm{l}$ of colloidal nanoparticles solution into the first column wells. By using an 8-channel micropipette mix the content and transfer $100 \mu \mathrm{l}$ to the rest of wells. Finally discard $100 \mu \mathrm{l}$ rather dispensing it in column 11 . About $5 \mu \mathrm{l}$ of bacterial suspension was dispensed into all wells of column 1 to 11 . The last two wells were used as positive (without antibiotics) and negative controls (left blank without inoculation and antibiotics) respectively. The microtitre plate was closed firmly and kept incubated at $37^{\circ} \mathrm{C}$ for $24 \mathrm{~h}$. After incubation, the microtitre plates were read at $595 \mathrm{~nm}$ using a microtitre reader (BIORAD). Nanomolar concentrations of silver nanoparticles used in the study were prepared by the methodology previously reported by Kumar et al. [13].

\section{Result and Discussion}

The use of plants in the biosynthesis of metal nanoparticles is a field currently under exploitation. In recent, the extent of silver nanoparticles has drawn the curiosity of many researchers since their biomedical and environmental applications. In the present study, we report on rapid biosynthesis of silver nanoparticle using A. squamosa leaf extract. The formation of silver nanoparticles is confirmed by the change in color (pale yellow to brown color) subsequent to the addition of 1 $\mathrm{mM}$ silver nitrate with leaf extract [14]. On the other hand, no reaction occurred in control solution $(1 \mathrm{mM}$ silver nitrate). The UV-vis absorption spectra of $A$. squamosa mediated biosynthesis of silver nanoparticles from leaf extract are displayed in Fig. 1. It is well known that surface plasmon resonance (SPR) of silver appears between 400 to $500 \mathrm{~nm}$.

Hence, the UV-Vis spectral analysis showed an absorption peak at $435 \mathrm{~nm}$ indicating the excitation of SPR [15]. Altogether, the spectral domain of colloidal solution exhibit broader electronic adsorption bands justifying the occurrence of small spherical silver nanoparticles [13]. Comparably, no such peaks were observed in control. We predict, the possible reduction

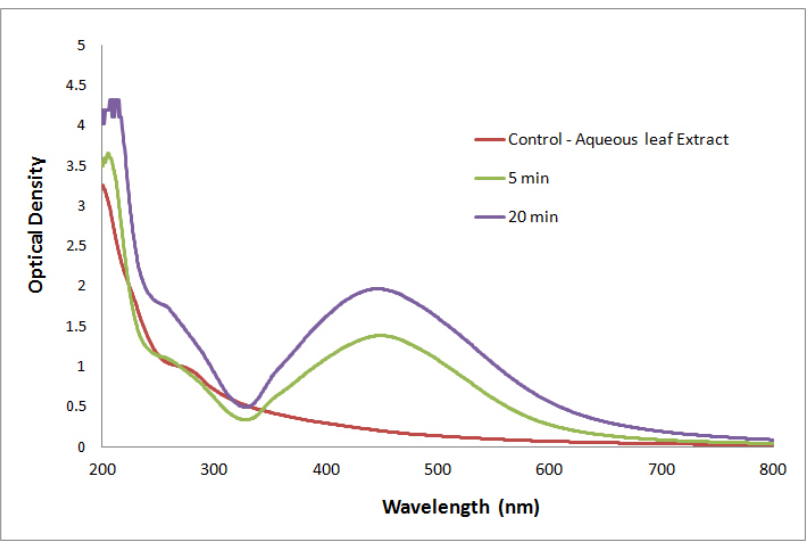

Fig. 1 UV-spectral analysis of silver nanoparticles synthesized from $A$. squamosa. 
http://nanobe.org

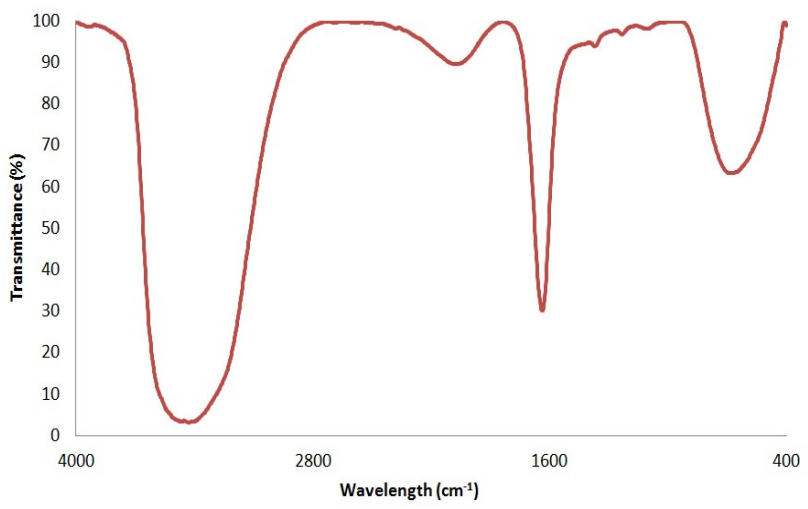

Fig. 2 FT-IR measurement of silver nanoparticles.

of silver ions could be due to the presence of bio-organic molecules in leaf extract. The occurrence of absorption bands between 200 to $230 \mathrm{~nm}$ indicates the electronic transition of metallic $\mathrm{Ag}^{+}$. The incidence of major FTIR spectral signatures at $3429 \mathrm{~cm}^{-1}, 1637 \mathrm{~cm}^{-1}$ and 685 $\mathrm{cm}^{-1}$ specify the existence of biomolecules as capping and stabilizing agents for nanoparticles (Fig. 2). A peak at $3429 \mathrm{~cm}^{-1}$ designates the pervasiveness of phenolic compounds with free $\mathrm{O}-\mathrm{H}$ group. The existence of peak at $1637 \mathrm{~cm}^{-1}$ and $685 \mathrm{~cm}^{-1}$ signify the presence alkenes

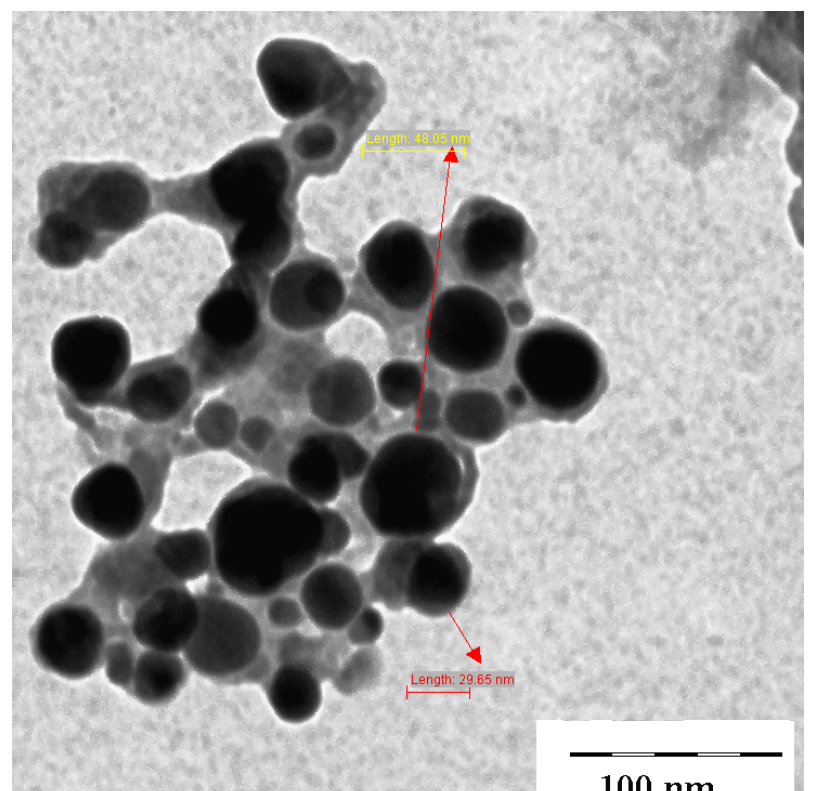

Fig. 3 Transmission Electron Microscopy of silver nanoparticles

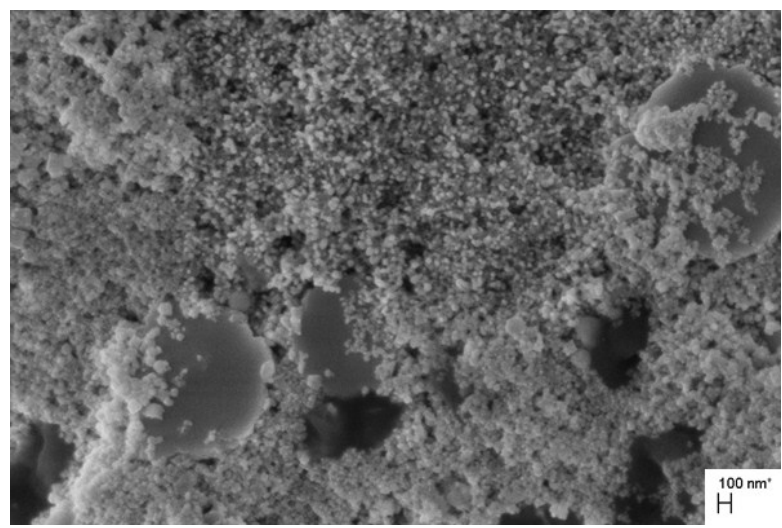

Fig. 4 Field Emission-Scanning Electron microscopic studies
$(\mathrm{C}=\mathrm{C})$ and $\mathrm{C}-\mathrm{H}$ deformation groups respectively. Based on our results, phenolic compounds play a foremost role in the formation of silver nanoparticles [16].

TEM analysis showed the presence of nano-sized spherical shaped metal particles with an average size of $52 \mathrm{~nm}$ (Fig. 3). Based on the excitation of SPR, $20 \mathrm{~min}$ is well sufficient for the formation of nanoparticles. In accordance with earlier findings [16,17], the formation of nanoparticles is rapid depicting narrow size distribution. The particles display inter-particular distance with no physical contact due to electrostatic repulsive force [3].

Concurrently, the morphological observation made by FE-SEM also revealed the presence of silver nanoparticles with an average particle of size ranged from 20-80 nm (Fig. 4). FE-SEM micrograph suggests, the particles found to be merely agglomerated at higher magnification as compared to TEM image. Previously, it was reported that tannins present in $A$. squamosa may encapsulate silver ions and thereby reducing its aggregation [16]. To summarize these results, the forma-tion of silver nanoparticles is attributed to the presence of reducing agents in the leaf extract of $A$. squamosa.

A typical XRD pattern reveal three intense peaks by $27.74,32.14$ and 46.14 in spectrum of $2 \theta$ value ranging from 10-80 (Fig. 5). The Braggs reflection at $\left(\begin{array}{lll}1 & 1 & 0\end{array}\right)$,

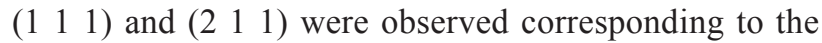
formation of silver oxide $\left(\mathrm{Ag}_{2} \mathrm{O}\right)$. Though, the plausible mechanism involved in the formation of $\mathrm{Ag}_{2} \mathrm{O}$ requires additional investigation. We assume, the formation of $\mathrm{Ag}_{2} \mathrm{O}$ may perhaps be due to coupling reaction with phenolic compounds. Earlier, we obtain similar kind of results in the biosynthesis of silver nanoparticles using seaweed, Ulva lactuca [18]. Altogether, a small peak at 38.14 indicates the formation of pure silver [19]. A few negligible spurious diffraction arises signifying the presence of impurities in the sample. The XRD pattern also reveals that silver nanoparticles formed are crystalline with an estimated size of $52 \mathrm{~nm}$ by the DebyeScherrer's formula, $d=\left(0.9 \lambda \times 180^{\circ}\right) / \beta \cos \theta \pi$.

Fig. 6 shows the measured zeta potential value of biosynthesized silver nanoparticles in the colloidal solution. The nanoparticles possess a negative zeta potential value of $-33.6 \mathrm{mV}$ and are highly stable due to electrostatic

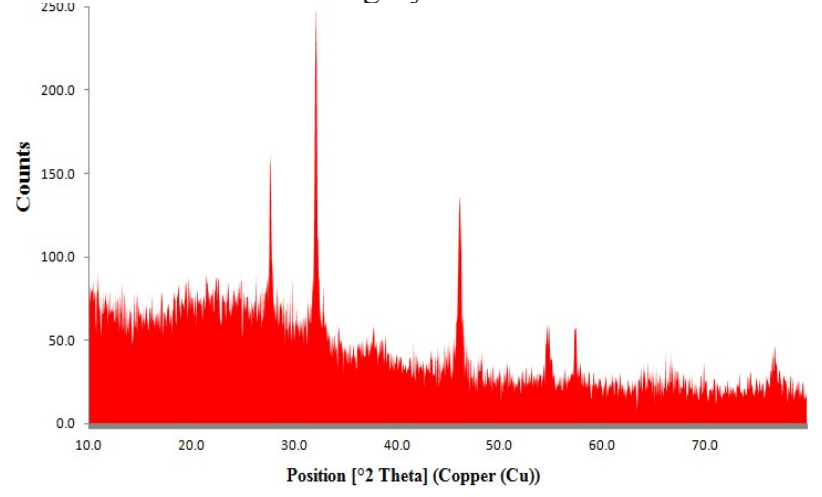

Fig. 5 X-ray diffraction measurement. 


\begin{tabular}{|c|c|c|c|c|}
\hline Results & & Mean $(m V)$ & Area $(\%)$ & Width (mV) \\
\hline Zeta Potential $(\mathrm{mV}):-33.6$ & Peak 1: & -33.6 & 100.0 & 5.20 \\
\hline Zeta Deviation (mV): 5.20 & Peak 2: & 0.00 & 0.0 & 0.00 \\
\hline $\begin{array}{c}\text { Conductivity }(\mathrm{ms} / \mathrm{cm}): 0.0900 \\
\text { Result quality : Good }\end{array}$ & Peak 3: & 0.00 & 0.0 & 0.00 \\
\hline
\end{tabular}

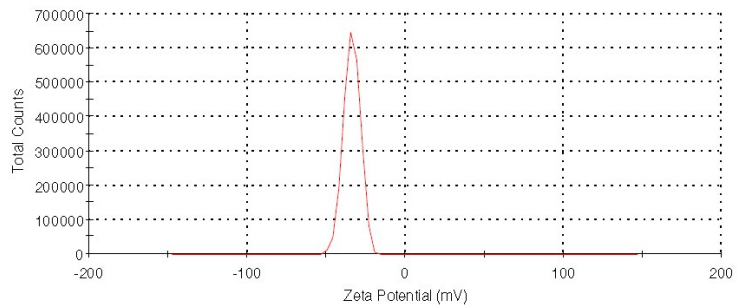

Fig. 6 Zeta potential measurement.

repulsive force. The particles with negative zeta potential strongly interact with cationic additives present in leaf extracts. Earlier report suggests zeta potential value of $-37 \mathrm{mV}$ presuming high stability at room temperature were obtained in A. squamosa [16]. Interestingly, the metal nanoparticles are stable over a period of month without any special storage in laboratory condition.

According to disk diffusion assay, the antimicrobial effect of silver nanoparticles depends on the ZoI surrounding the sterile disks. This is conceivably because, silver nanoparticles exhibit a wide range of effects which inhibits the growth, loss of infectivity and finally lead to cell death [4]. The above process mainly depends on the susceptibility of microbial species with reference to size [20], shape [21] and concentration of silver nanoparticles [22]. The maximum ZoI by disk diffusion assay based on volume centered at $25 \mu \mathrm{l}(13.1 \mathrm{~mm})$ followed by $20 \mu \mathrm{l}$ (10 mm), $15 \mu \mathrm{l}(7.2 \mathrm{~mm}), 10 \mu \mathrm{l}(4.1 \mathrm{~mm})$ and $5 \mu \mathrm{l}(1.9$ $\mathrm{mm}$ ) respectively (Fig. 7). The capping agents present in silver nanoparticles may play a major role in determining the bactericidal effect by enhancing the surface charge density and chemical properties [23]. We also inferred,

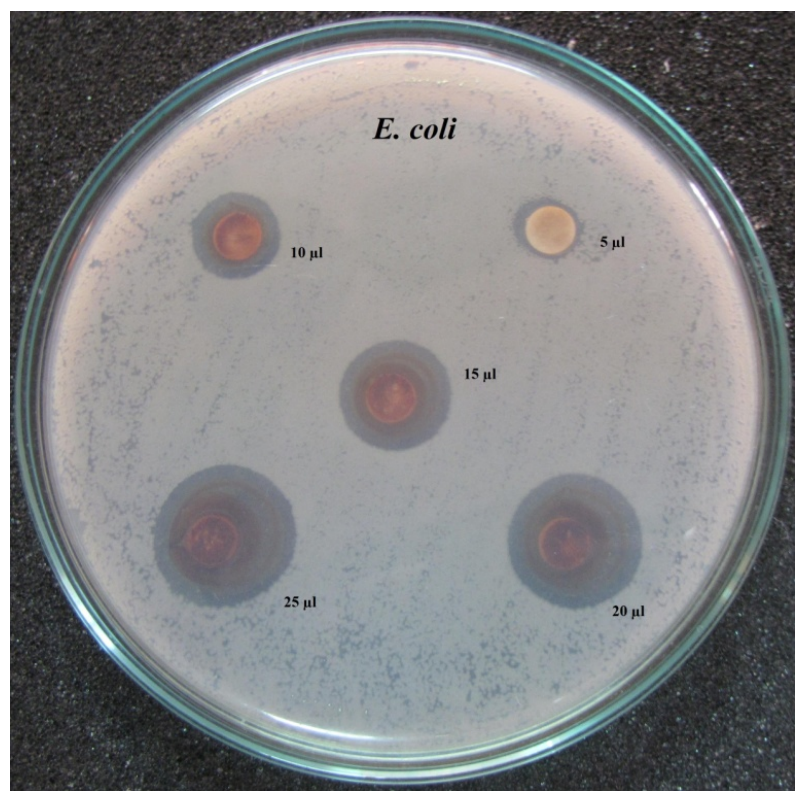

Fig. 7 Disk diffusion assay at different volumes.
$E$. coli is significantly more susceptible to nanoparticles synthesized from A. squamosa leaf extract. However, no inhibition zone occurred in the control (sterile disk) and aqueous leaf broth indicating the absence of antimicrobial activity (data not shown).

For comparative analysis, the antibacterial activities of silver nanoparticles were tested by using the microtitre broth dilution method. The study reveals the minimum inhibitory concentration $\left(\mathrm{MIC}_{50}\right)$ of silver nanoparticles synthesized by green approach centered at 12.50 nM concentrations (Fig. 8). Further, no promising growth $\left(\mathrm{MIC}_{90}\right)$ of $E$. coli cells at 100,50 and $25 \mathrm{nM}$ concentration occurred. As a result, we deem that free radicals from nanoparticles may rupture the cell membrane and depress the activity of membranous enzymes which tend bacteria to eventually die [24]. On the whole, high dosage of silver nanoparticles may perhaps be needed to inactivate or hinder the bacterial growth. Numerous studies have shown the antibacterial effect of silver nanoparticles but still the mechanism involved is unclear and requires further investigation. For the first time, we confer comparative antibacterial effects of silver nanoparticles by disk diffusion and microtitre broth dilution method. The disk diffusion method allows rapid screening of antimicrobials in an efficient and effective manner.

Nevertheless, the measurement is considered to be quantitative describing the susceptibility of antimicrobials based on the ZoI $[25,26]$. The major downside of this method is unable to develop minimum inhibitory concentration for any bacterial species. Conversely, the microtitre broth dilution method is a qualitative method that proficiently generates minimum inhibitory concentration [12]. Microtitre broth dilution method requires less labour, chemicals and cost effective to screen antimicrobials against numerous bacterial species. It allows rapid screening of microbes by determining the minimum inhibitory concentration compared to other in vitro methods. Therefore our study suggests microtitre broth dilution method is more convenient than the disk diffusion method. On the other hand, additional investigation is required to demonstrate the biosafety of silver nanoparticles in animal models before they enter clinical trials.

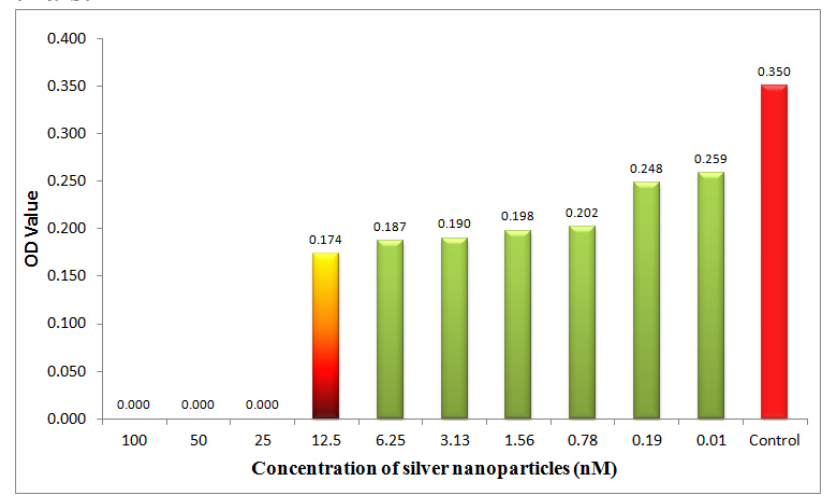

Fig. 8 Microtitre broth dilution method. 


\section{Conclusion}

To conclude, we report on green, rapid, biosynthesis of silver nanoparticles from A. squamosa leaves extract. Further, the evidence shown by high throughput techniques like UV-visible spectroscopy, FT-IR, electron microscopic studies, XRD and Zeta potential measurement indicate the occurrence of silver nanoparticles. The antibacterial activity of silver nanoparticles is impressive in hampering the growth of E. coli. Our result show, microtitre plate method is appropriate compared to disk diffusion assay by determining minimum inhibitory concentration of silver nanoparticles against $E$. coli. Further, investigations are underway to identify the possible mechanism involved in the bactericidal activity of silver nanoparticles synthesized by $A$. squamosa.

\section{Acknowledgements}

The authors are thankful to Dr. K. Jeganathan, Professor, V, Puroshothaman, P. Sundara Venkatesh and V. Rajiu, Research Scholars (Centre for Nanoscience and Technology, School of Physics, Bharathidasan University, Tiruchirappalli - 24) for their help in FESEM and DLS analysis. We also thank Dr. K. Premkumar, Assistant Professor, (Department of Biomedical Science, Bharathidasan University, Tiruchirappalli, Tamil Nadu) for his valuable suggestion during the course of work.

\section{References}

1 Konwarh R., Gogoi B., Philip R., Laskar M.A., Karak N. Biomimetic preparation of polymer-supported free radical scavenging, cytocompatible and antimicrobial "green" silver nanoparticles using aqueous extract of Citrus sinensis peel. Colloids Surf B Biointerf. 2011, 84:338-345.

2 Ramanathan R., O’Mullane A.P., Parikh R.Y., Smooker P.M., Bhargava S.K., Bansal V. Bacterial Kinetics controlled shapedirected biosynthesis of silver nanoplates using Morganella psychrotolerans. Langmuir, 2010, 27:714-719.

3 Sathishkumar M., Sneha K., Won S.W., Cho C.W., Kim S., Yun Y.S. Cinnamon zeylanicum bark extract and powder mediated green synthesis of nano-crystalline silver particles and its bactericidal activity. Colloids Surf B Biointerf. 2009, 73: 332.

4 Lara H.H., Garza-Trevino E.N., Ixtepan-Turrent L., Singh D.K. Silver nanoparticles are broad-spectrum bactericidal and virucidal compounds. Journal of Nanoparticles 2011, 9:30.

5 Iravani S. Green synthesis of metal nanoparticles using plant. Green Chem. 2010, 13:2638-2650.

6 Korbekandi H., Iravani S. Silver Nanoparticles, The Delivery of nanoparticles, In: Dr. Abbass A. Hashim, editor. The Delivery of Nanoparticles, InTech, China, 2012, pp. 3-36.

7 Pandey N., Barve D. Phytochemical and pharmacological review on Annona squamosa Linn. Int J Biomed Pharma Sci. 2011, 2: 1404-1412.

8 Vanitha V., Umadevi K.J., Vijayalakshmi K. Determination of Bioactive Components of Annona squamosa L. Leaf by GC- MS Analysis. Int J Pharma Sci Drug Res. 2011, 3:309-312.

9 Kumar P., Senthamilselvi S., Govindaraju M. Seaweed-mediated biosynthesis of silver nanoparticles using Gracilaria corticata for its antifungal activity against Candida spp. Appl Nanosci. 2012.

10 Kumar P., Senthamilselvi S., Lakshmiprabha A., Selvaraj M., Macklin Rani L., Suganthi P., Sarojini Devi B., Govindaraju M. Antibacterial activity and in-vitro cytotoxicity assay against brine shrimp using silver nanoparticles synthesized from Sargassum ilicifolium. Dig. J. Nanomater. Bios. 2012a, 7(4):1447-1455.

11 Kirby W.M.M., Yoshihara G.M., Sundsted K.S., Warren J.H. Clinical usefulness of a single disc method for antibiotic sensitivity testing. Antibiotics Annu. 1956-1957:892-897.

12 Goldstein E.J., Cherubin C.E., Shulman M. Comparison of microtiter broth dilution and agar dilution methods for susceptibility testing of Eikenella corrodens. Antimicro Agents Chemother. 1983, 23:42-45.

13 Kumar P., Senthamilselvi S., Lakshmipraba A., Premkumar K., Muthukumaran V.R., Ganeshkumar R.S., Visvanathan P., Govindaraju M. Efficacy of bio-synthesized silver nanoparticles using Acanthophora spicifera to encumber biofilm formation. Dig J Nanomater Bios. 2012b, (2):511-522.

14 Mulvaney P. Surface Plasmon spectroscopy of nanosized metal particles. Langmuir 1996, 2:788-800.

15 Krishnaraj C., Jagan E.G., Rajasekar S., Selvankumar P., Kalaichelvan P.T., Mohan N. Synthesis of silver nanoparticles using Acalypha indica leaf extracts and its antibacterial activity against water borne pathogens. Colloids Surf B Biointerf. 2010, 76:50-56.

16 Vivek R., Thangam R., Muthuchelian K., Gunasekaran P., Kaveri K., Kannan S. Green biosynthesis of silver nanoparticles from Annona squamosa leaf extract and its in vitro cytotoxic effect on MCF-7 cells. Process Biochem. 2012, 47:2405.

17 Kumar R., Roopan S.M., Prabhakaran A, Khanna VG, Chakroborty S. Agricultural waste Annona squamosa peel extract: biosynthesis of silver nanoparticles. Colloids Surf B: Biointerf. 2012, 90:173176.

18 Kumar P., Govindaraju M., Senthamilselvi S., Premkumar K. Photocatalytic degradation of methyl orange dye using silver (Ag) nanoparticles synthesized from Ulva lactuca. Colloids Surf B: Biointerf. 2013c, 103:658-661.

19 Boopathi S., Gopinath S., Boopathi T., Balamurugan V., Rajeshkumar R., Sundaraman M. Characterization and Antimicrobial Properties of Silver and Silver Oxide Nanoparticles Synthesized by Cell-Free Extract of a Mangrove-Associated Pseudomonas aeruginosa M6 Using Two Different Thermal Treatments. Ind Eng Chem Res. 2012, 51:5976-5985.

20 Yen H.J., Hsu S.H., Tsai C.L. Cytotoxicity and immunological response of gold and silver nanoparticles of different sizes. Small 2009, 5:1553-1561.

21 Pal S., Tak Y.K., Song J.M. Does the antibacterial activity of silver nanoparticles depend on the shape of the nanoparticle? A study of the gram-negative bacterium Escherichia coli. Appl Environ Microbiol. 2007, 73:1712.

22 Asharani P.V., Hande M.P., Valiyaveettil S. Anti-proliferative activity of silver nanoparticles. BMC Cell Biol. 2009, 10:65.

23 Albanes A., Tang P.S., Chan W.C.W. The Effects of Nanoparticle Size, Shape, and Surfaces Chemistry on Biological Systems. Annu Rev Biomed Eng. 2012, 14:1-16.

24 Li W.R., Xie X.B., Shi Q.S., Zeng H.Y., Ou-Yang Y.S., Chen Y.B. Antibacterial activity and mechanism of silver nanoparticles on Escherichia coli. Appl. Microbiol. Biotechnol. 2010, 85:11151122.

25 Andrews J.M. Determination of minimum inhibitory concentration. $J$ Antimicrob Chemother. 2001, 48:5-16.

26 Yu D.G. Formation of colloidal silver nanoparticles stabilized by $\mathrm{Na}^{+}$-poly ( $\gamma$-glutamic acid)-silver nitrate complex via chemical reduction process. Colloids Surf B Biointerf. 2007, 59:171-178.

Copyright:(c) 2013 S. Senthamilselvi et al. This is an openaccess article distributed under the terms of the Creative Commons Attribution License, which permits unrestricted use, distribution, and reproduction in any medium, provided the original author and source are credited. 